\title{
Evaluation of Sensor Based Residential Irrigation Water Application
}

\author{
Melissa B. Haley ${ }^{1}$, Michael D. Dukes ${ }^{2}$, Grady L. Miller ${ }^{3}$ \\ Paper presented at the $27^{\text {th }}$ Annual International Irrigation Show \\ San Antonio, TX \\ November 5-7, 2006
}

\begin{abstract}
An irrigation study to determine the effects of sensor based irrigation controllers on residential irrigation water use is described in this paper. This project is comprised of 64 homes in Pinellas County, Florida, with automatic in-ground residential irrigation systems. Homes for this study were categorized into three groups of water users based on historic water use; low (20-36 $\mathrm{mm} / \mathrm{month})$, medium (40-87 mm/month), and high (92-214 mm/month). Experimental treatments to be evaluated include an automatic time based irrigation controller, set and operated by the cooperator, the integration of a soil moisture sensor, a rain sensor, and a rain sensor along with educational material given to the cooperator. Our hypothesis is that the use of soil moisture sensors, rain sensors, and educational materials will reduce residential irrigation water application.
\end{abstract}

\section{Introduction}

Nearly all new homes in Florida are constructed with in-ground automatic irrigation systems. Studies have shown that residential lawn and landscape irrigation can account for more than 64\% of the total water use for a single family home (Haley et al., 2006). Furthermore, recent research in Florida has indicated that homeowners are over irrigating, by irrigating more the plant water needs based on local evapotranspiration rate and precipitation (Haley et al., 2006). Irrigation water use conservation efforts are necessary due to the rise in the state's population. The South West Florida Water Management District (SWFWMD), which is one of five Florida water management districts, accounts for a quarter of the State's overall population, with more than four million inhabitants. Between 1990 and 2000, the population within the District grew by over 640,000 residents, approximately $19 \%$, and is projected to increase another 1.8 million by 2025. The 2000 population for Pinellas County, the study area, was 921,482 and is forecasted to be $1,078,600$ by 2025 , an increase of $17 \%$.

Within the SWFWMD, public water use accounts for $42 \%$ if the total freshwater use, the second largest water use sector after agriculture. Although there has been considerable population growth, the water use amount has remained fairly constant from 1993-2002. This is a result of an 11\% decrease in per capita water use, from 533 to $476 \mathrm{~L} / \mathrm{d}$. However, when the per capita water use is normalized for drought or excessively wet seasons; the total public water use shows an

\footnotetext{
${ }^{1}$ Irrigation Research Coordinator, Agricultural and Biological Engineering Dept., University of Florida, Gainesville, FL 32611, tel: (352) 392-1864 x263, email: mhaley@ifas.ufl.edu

${ }^{2}$ Associate Professor, Agricultural and Biological Engineering Dept., University of Florida, Gainesville, FL 32611, email: mddukes@ufl.edu

${ }^{3}$ Professor, Crop Science Department, North Carolina State University, Raleigh, NC, 27695, email: grady_miller@ncsu.edu
} 
upward trend. It is expected that as population growth continues, public water use will become the dominant water use sector. According to the SWFWMD 2005 District Management Plan, the projected water demand for the public supply is expected to increase to 845 million L/d (SWFWMD, 2005). More than 80\% if this water withdrawn from groundwater sources, most of which comes from the Floridan aquifer, which has increasingly been regarded as a limited resource. Within the SWFWMD, the exclusive source of natural replenishment to the Floridan aquifer is from precipitation.

Although within the Water Management District, twice weekly landscape irrigation is permitted, Pinellas County has more stringent water use regulations. In accordance with Pinellas County Code 82-2, irrigation within Pinellas County is only authorized for one day a week (PCU, 2006a). Watering is prohibited between the hours of 8:00 am and 6:00 pm. The current rate for potable water from Pinellas County Utilities is $\$ 3.60$, and will increase to $\$ 4.04$ as of October 1 , 2006 for 3780 L (PCU, 2006b). According to the Florida Water Rates Evaluation of SingleFamily Homes, completed in 2005, the main concern of homeowners with respect to increased costs is outdoor use (Whitcomb, 2005).

In a study on residential irrigation efficiency with the St. Johns River Water Management District (SJRWMD), on average, 64\% of the water in individual homes went to irrigation. In the summer months this percentage increased as high as 88\%. The study also showed that setting irrigation controllers with respect to historical turfgrass seasonal water needs resulted in a 30\% reduction of irrigation water applied (Haley et al., 2006). During this study it was observed that the homeowners did not have a clear understanding of when and how much to irrigate. With the combination of substantial microirrigated landscape planting areas, and irrigation based on historical evapotranspiration rates, the fraction of water use for irrigation purposes was decreased on average by $50 \%$ (Haley et al., 2006).

Sensor based technology can result in irrigation water savings. Typically, a soil moisture sensor is buried in an irrigated area, and an adjustable threshold controller is mounted near the irrigation system time clock. This sensor can result in the bypass of scheduled irrigation events based on soil moisture content. Soil moisture sensors have been shown to reduce irrigation water use under rainy conditions up to 70\%, with no decline in turf quality (Cardenas-Lailhacar et al., 2005). Rain sensors are the most common type of senor used in conjunction with automatic irrigation systems. They should be installed in an area unobstructed from rainfall and after a rain event the sensor causes the system to bypass to prevent unnecessary irrigation similar to soil moisture sensors. All irrigation systems in Florida installed since 1991 are required to have a functioning rain sensor (Florida Statutes, Chapter 373.62). However, this statute is not typically enforced (Whitcomb, 2005). According to University of Florida research, systems which incorporate rain sensors used 31\% less water than systems without a functioning rain shut-off device (Cardenas-Lailhacar et al., 2005).

The objectives of this study are to assess the effect of soil moisture sensor control, rain sensors, and educational materials for irrigation scheduling on residential irrigation water use in Southwest Florida. 


\section{Materials and Methods}

The homes included in this research project are all located in the City of Palm Harbor in Pinellas County which is part of the Pinellas-Anclotte River Basin within the South West Florida Water Management District. The target number of cooperators is 64. Currently, 58 residential cooperators with automatic in-ground irrigation systems have been recruited. The county was divided into quadrants, based on weather station proximity, denoting a location number for each home (Figure 1).

(L1) Northwest quadrant

(L2) Southwest quadrant

(L3) Southeast quadrant

(L4) Northeast quadrant

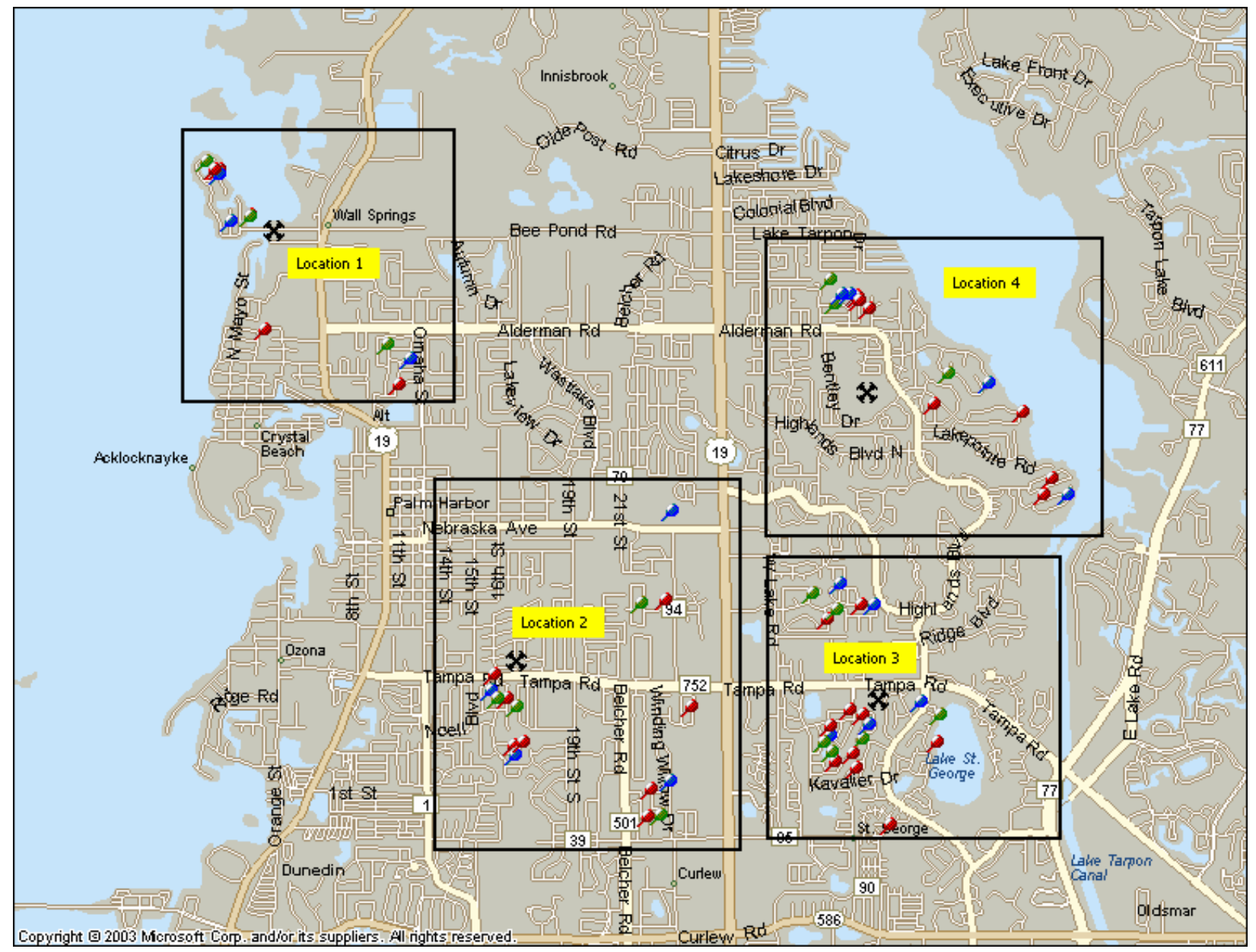

Figure 1. Map of the City of Palm Harbor in Pinellas County Florida, with homes denoted by pins and weather station locations marked by an " $\mathrm{x}$ ".

Pinellas County has a humid subtropical climate, with frost and freezing temperatures occurring at least once annually. The average annual rainfall within the SWFWMD is $1350 \mathrm{~mm}$, with 60$65 \%$ occurring between in the summer months when evapotranspiration rates are highest. The groundwater supply in southwest Florida comes from the Floridan aquifer. This aquifer is primarily dependant on the rainfall which occurs in the district as the sole source of natural replenishment (SWFWMD, 2005). 
To measure the climactic parameters and precipitation, a weather station (Figure 2) was installed in each of the four locations (Figure 1). The stations were centered within a $2 \mathrm{~km}$ radius of the homes. The station sites were county owned and managed properties, with flat-grassed areas and minimal canopy coverage of at least $61 \mathrm{~m}$ distance if possible. Date, time, relative humidity and temperature (model HMP45C, Vaisala, Inc., Woburn, MA), solar radiation (model LI200X, LiCor, Inc., Lincoln, NE), wind speed and direction (model WAS425, Vaisala, Inc., Sunnyvale, CA) and, precipitation (model TE525WS, Texas Electronics, Inc., Dallas, TX), are recorded in 15 minute intervals via a CR10X data logger (Campbell Scientific, Inc., Logan UT). To determine whether over irrigation has occurred, the amount of irrigation water use will be compared to crop evapotranspiration $\left(\mathrm{ET}_{\mathrm{c}}\right)$ which is calculated as the product of reference evapotranspiration $\left(\mathrm{ET}_{\mathrm{o}}\right)$ and a crop coefficient $\left(\mathrm{K}_{\mathrm{c}}\right)$. Effective rainfall will also be considered. $\mathrm{ET}_{\mathrm{o}}$ will be determined by ASCE-EWRI standardized Penman-Monteith equation (ASCE-EWRI, 2004).

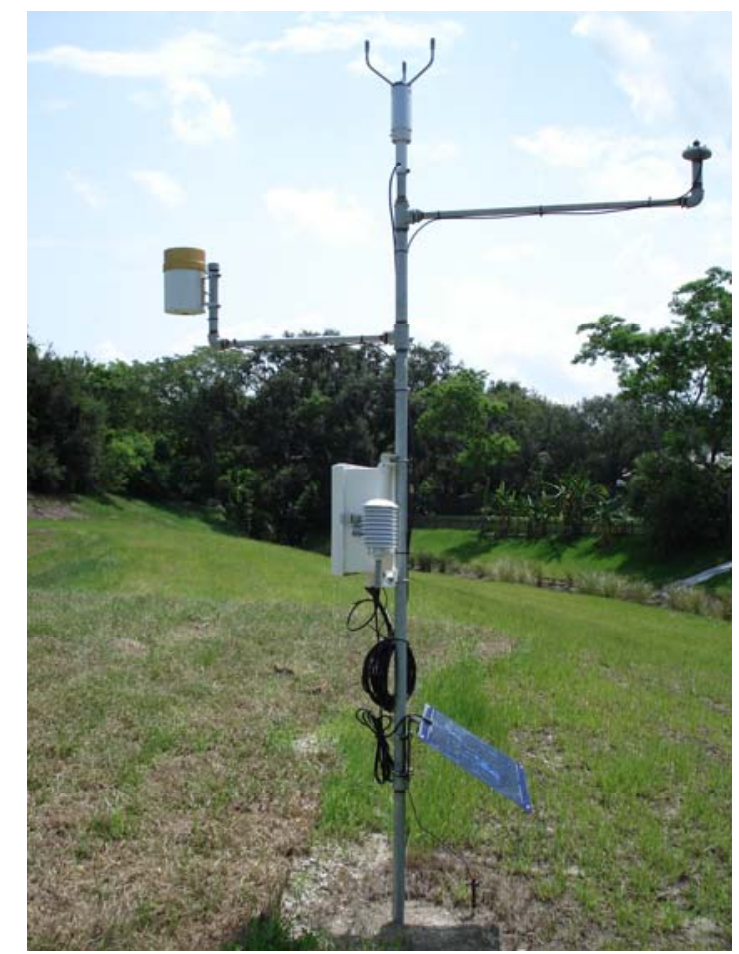

Figure 2. One of the weather stations located in Pinellas County.

Household water consumption, both total and water used for irrigation purposes only will be recorded by weekly flow meter readings. All of the homes included in this study obtain water from Pinellas County Utilities. The utility water meter will be used to determine the total (indoor plus outdoor) amount of water consumed by the household. A flow meter was also installed in the irrigation mainline to determine the volume of irrigation water used. Positive displacement flow meters were purchased due to their accuracy and convenience (Baum et al., 2003), and installed by a local contractor on each of the cooperating residential homes. The meters were installed with no obstruction within approximately ten diameters of the inlet and outlet of the meter when possible. This was to ensure minimal turbulence in flow through the meter to maintain accuracy. 


\section{Treatments}

The homes were divided into four experimental treatments. The treatment classifications refer to the additional educational materials or sensor based technology incorporated into the systems.

(T1) Treatment one: Current irrigation system with soil moisture sensor set at $10 \%$ volumetric soil water content (approximately field capacity)

(T2) Treatment two: Current irrigation system with rain sensor

(T3) Treatment three: Current irrigation system with no additional sensor

(T4) Treatment four: Current irrigation system with rain sensor and educational materials

The educational materials will include brochures of outdoor water saving tips developed by the SWFWMD and a customized irrigation run time card (Figure 3).

\section{Irrigation Runtimes in Minutes}

Use the following table to set your irrigation system for seasonal water use. The zone runtimes have been calculated for your system based on once day per week irrigation. These are guidelines and set to help you conserve water, you can water more or less if you notice inadequate water application in the landscape. Please call the University with any major changes to the suggested runtimes so we may update our records or your water practices.

\begin{tabular}{|c|c|c|c|c|}
\hline Season & Zone 1 & Zone 2 & Zone 3 & Zone 4 \\
\hline $\begin{array}{c}\text { Winter } \\
\text { (Dec., Jan., Feb.) }\end{array}$ & & & & \\
\hline $\begin{array}{l}\text { Spring } \\
\text { (Mar., Apr.) }\end{array}$ & & & & \\
\hline $\begin{array}{c}\text { Summer } \\
\text { (May, Jun., Jul., Aug.) }\end{array}$ & & & & \\
\hline $\begin{array}{c}\text { Fall } \\
\text { (Sep., Oct., Nov.) }\end{array}$ & & & & \\
\hline
\end{tabular}

Your Zone Locations and sprinkler types:

Zone 1 - Front turf and bedding, combination of spray and rotor heads

Zone 2 - Front right side, spray heads.

Zone 3 - Right side and back, combination of spray and rotor heads.

Zone 4 - Left side and back bedding, combination of spray and rotor heads.

Figure 3. Front of sample irrigation scheduling card.

Each home in the treatment will receive a run time card that is based on the home's specific system design and zone layout. The card will be laminated and can be affixed to the controller box.

\section{Background Analysis}

Residential water use data, consisting of both indoor and outdoor use, were analyzed based on two year historic data for each home. Bimonthly data, from April, 2003 to October, 2005, was provided by Pinellas County Utilities. To estimate the bimonthly irrigation water use, the indoor water use was subtracted from the total water use, by assuming that indoor water use was the minimum bimonthly consumption over the two year period if less than 15,000 L. This value was determined as the average indoor water use across all homes. The irrigation water use in volume was then divided by $85 \%$ of the non-structural land area to determine the irrigation application per given time period. In a previous study conducted with SJRWMD, on average the irrigated area was 85\% of the non-structural area (Haley et al., 2006). The non-structural land area for each home was calculated from county parcel records and it was assumed that all of this area was 
irrigated. Once the bimonthly irrigation water use was estimated, each home was then categorized into an irrigation tendency classification. These classifications were based on quartiles where the low quartile was "low", two next quartiles (2 and 3) were "medium" and the upper quartile was classified as "high" irrigation users. Homes from each of these water use tendencies were approximately evenly distributed across the four treatments. From the provided data, 26\% of the homes were low irrigation water users and had an average irrigation water application of $30 \mathrm{~mm}$ per month of water for outdoor use. Medium water users accounted for $48 \%$ of the homes and consumed an average of $62 \mathrm{~mm}$ of water for outdoor use monthly. The high water users had an average of $134 \mathrm{~mm}$ of water per month for outdoor use and comprised the upper $26 \%$ of the sample.

Table 1. Historical water use statistics.

\section{Est. Outdoor Water Use} (mm/30d)

\begin{tabular}{cccc}
\hline Group & Average & Min. & Max. \\
\hline Low & 30 & 20 & 36 \\
Medium & 62 & 40 & 87 \\
High & 134 & 92 & 214 \\
\hline
\end{tabular}

Compared to a study in the Central Florida ridge, the water usage for the data analyzed here was slightly less. The average outdoor water use for the homes in the SJRWMD study ranged from 80-140 mm/month (Haley et al., 2006) compared to 30-134 mm/month.

\section{Irrigation Evaluations}

System evaluations were conducted for each home included in the study. The evaluation is a means of quantifying the irrigation system performance. Irrigation cycle water consumption is computed by recording the actual flow rate for each zone multiplied by the zone run time.

During this evaluation any required maintenance resulting from broken heads and leaks is noted. Any maintenance that would compromise the uniformity test was fixed before the testing began.

An estimation of system distribution uniformity $\left(\mathrm{DU}_{\mathrm{lq}}\right)$ was calculated by performing a catch-can test following the Mobile Irrigation Lab Handbook guidelines for Florida (Micker, 1996). $\mathrm{DU}_{\mathrm{lq}}$ can be calculated with the following equation (Merriam and Keller, 1978):

$$
D U_{l q}=\frac{\bar{D}_{l q}}{\bar{D}_{t o t}}
$$

where, $\bar{D}_{l q}$ is the lowest quarter of the average of a group of catch-can measurements and $\bar{D}_{\text {tot }}$ is the total average of a group of catch-can measurements.

Uniformity of water distribution measures the relative application depth over a given area. This concept can assign a numeric value to quantify how well a system is performing. The term uniformity refers to the measure of the spatial differences between applied waters over an irrigated area. The average $\mathrm{DU}_{\mathrm{lq}}$ of the sampling of the 53 homes tested to date in this study is 0.61, ranging from 0.29 to 0.85 . Compared to the Irrigation Association distribution uniformity quality ratings for an irrigation system (IA, 2005), 58\% the homes in this study can be classified as "good" or better (Figure 4). Although nearly a quarter of the homes are lower than "fair", the landscape quality is generally acceptable in most cases. Less than acceptable irrigation system $\mathrm{DU}_{\mathrm{lq}}$ ratings do not necessarily result in poor landscape quality in Florida (Baum et al., 2005). 


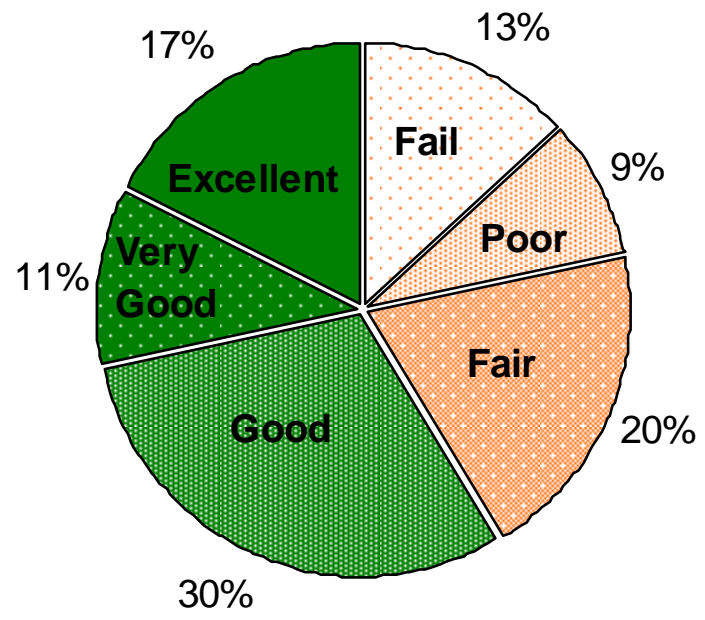

$\square$ Fair (DU<0.40)

Door (0.40-0.49)

$\square$ Fair (0.50-0.59)

圈 Good (0.60-0.69)

$\square$ Very Good (0.70-0.74)

$\square$ Excellent (DU>0.85)

Figure 4. Irrigation system quality ratings related to low quarter distribution uniformity (IA, 2005).

Initially every home was given a visual inspection and assigned a numeric value based on landscape level (Figure 5). The landscape level is based on the percentage turfgrass versus bedded areas.

(LL1) Turfgrass comprises a greater area then bedded landscape area

(LL2) Turfgrass and bedded areas comprise equal parts of the landscape

(LL3) Turfgrass comprises a lesser area then bedded landscape area

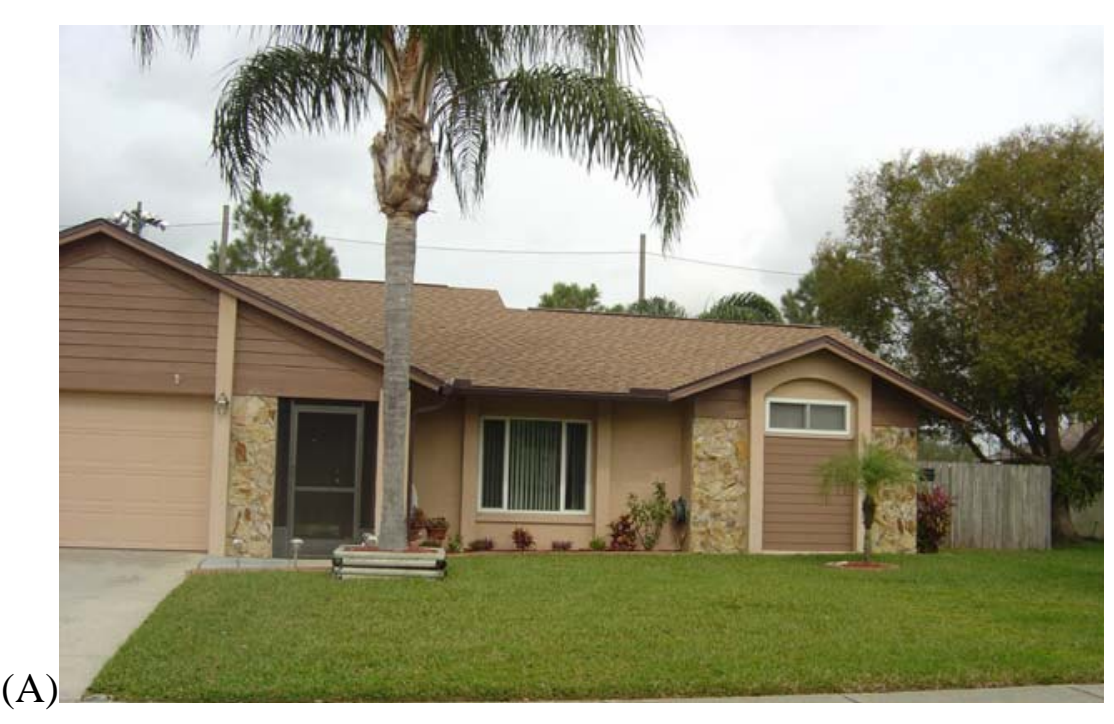




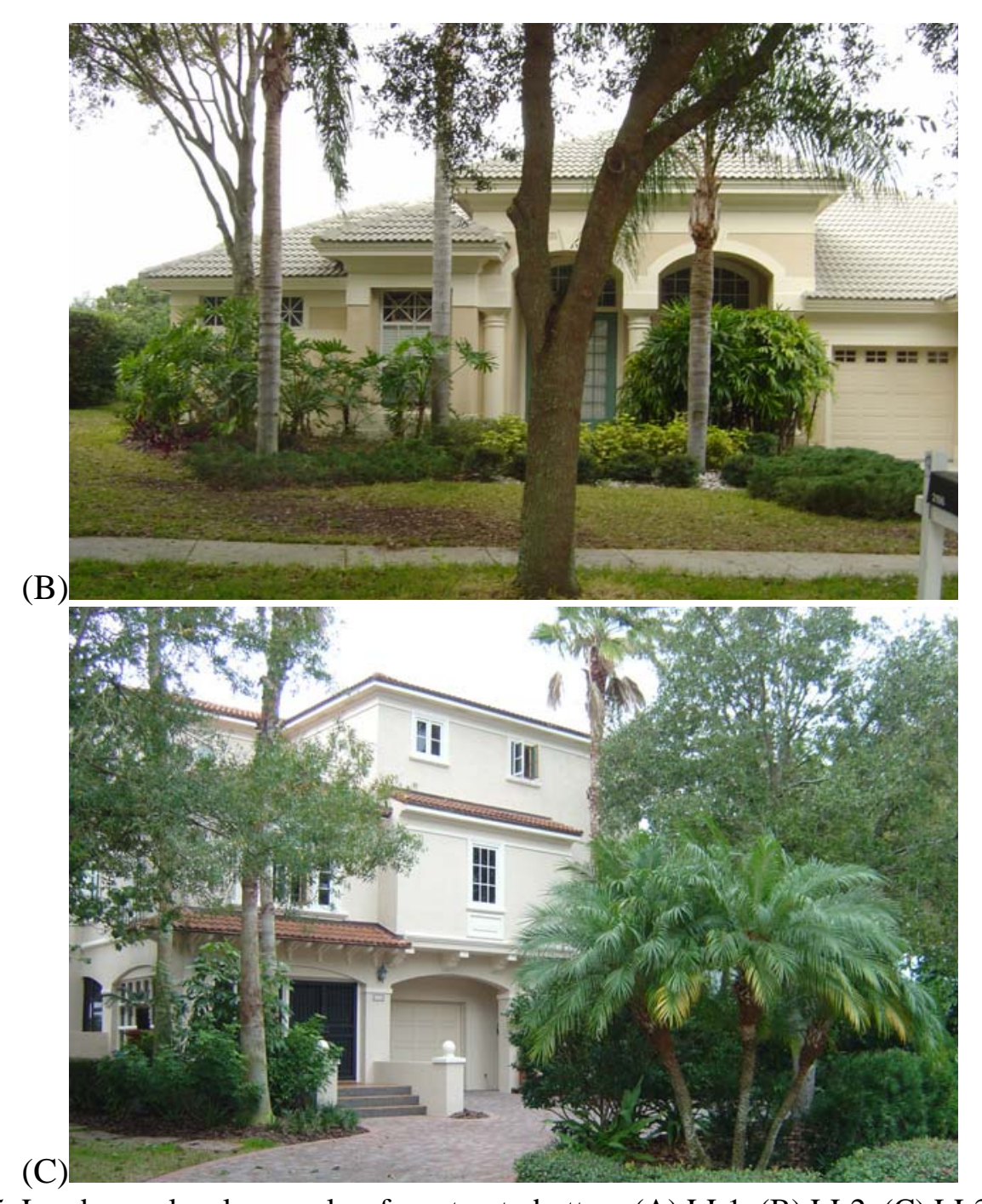

Figure 5. Landscape level examples, from top to bottom (A) LL1, (B) LL2, (C) LL3.

Turf quality ratings can quantify the overall appearance of the turfgrass area and as a measure of functional use and aesthetics (Figure 6). Initial turf quality ratings were taken for each home during the irrigation evaluations, as a baseline standard of comparison for each home. The assessment of turfgrass is a subjective process following the National Turfgrass Evaluation Procedures (NTEP) (Shearman and Morris, 1998). This assessment is based on visual estimates such as color, stand density, leaf texture, uniformity, disease, pests, weeds, thatch accumulation, drought stress, traffic, and quality. The rating scale is from 1-9, with 1 being lowest and 9 being highest possible. A rating of 5 is considered minimally acceptable. Turf quality will be rated at each house seasonally throughout the duration of the study. 


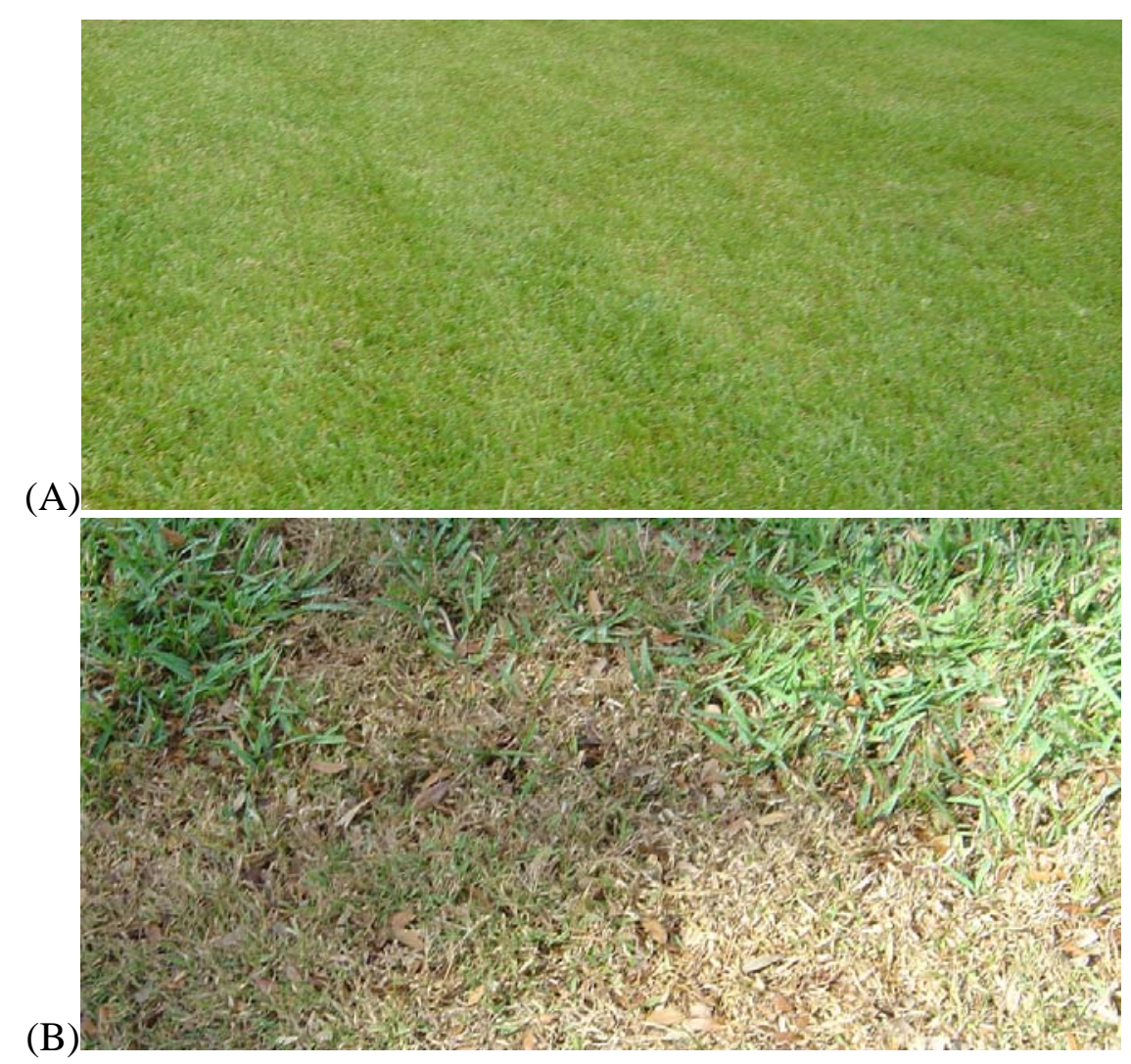

Figure 6. Turf quality examples, (A) high, (B) poor.

\section{Weather Data Quality Control}

To determine the actual amount of irrigation needed, evapotranspiration is calculated from the weather parameters logged from sensors at each weather station. Since the calculated $\mathrm{ET}_{\mathrm{o}}$ relies on the collected data quality, weather data integrity and quality assurance must be assessed (ASCE-EWRI, 2004). In addition to data assessment, routine maintenance must be performed to ensure the proper functionality of the weather station. Technical maintenance includes the evaluation, repair and replacement of equipment, while non-technical site maintenance includes removal of debris from tipping bucket, cleaning solar panel, bird prevention, mowing, etc.

Common methods for quality assessments are done by comparing incoming parameters against relevant physical extremes, employing statistical techniques to find extreme or anomalous values, and comparing neighboring stations. Quality control for the weather data collected in this study, evaluated three primary weather parameters: solar radiation, temperature, and wind speed.

Solar radiation is measured by a pyranometer (model LI200X, Li-Cor, Inc., Lincoln, NE). To check the operation and calibration of the pyranometer, the daily average readings for solar radiation $\left(\mathrm{R}_{\mathrm{s}}\right)$ can be plotted against computed clear sky conditions $\left(\mathrm{R}_{\mathrm{so}}\right)$ (Figure 7). All $\mathrm{R}_{\mathrm{s}}$ values should fall below the $R_{s 0}$ curve. Cloud free days are indicated by $R_{s}$ values near the $R_{s o}$ curve. When $R_{s}$ is below the $R_{s o}$ curve cloudy or hazy days are indicated. These plots can also show shifts in the time stamp associated with the data set. 


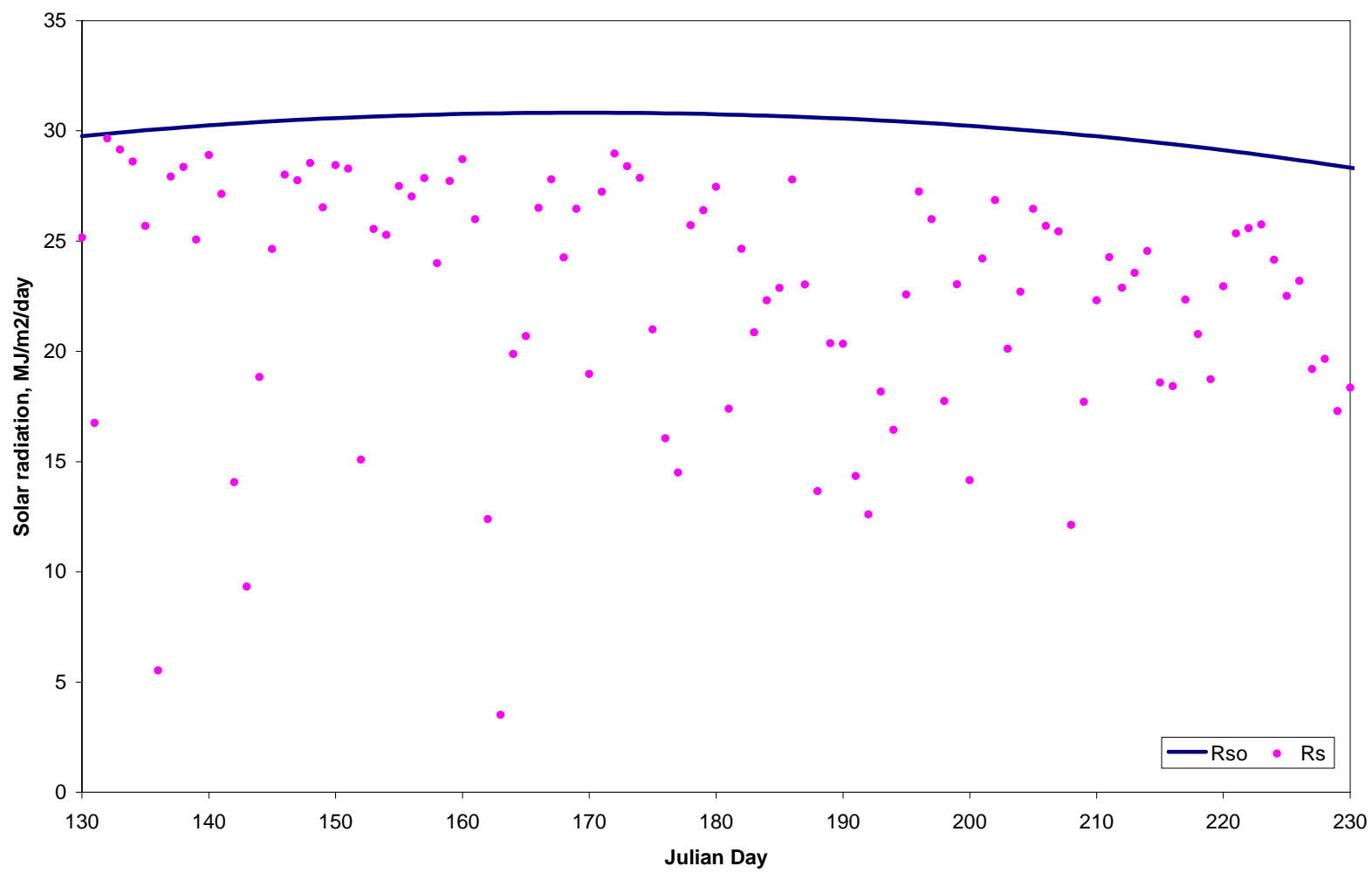

Figure 7. Daily measured $\mathrm{R}_{\mathrm{s}}$ and calculated $\mathrm{R}_{\mathrm{so}}$ recorded from Loc1, Palm Harbor, FL during 2006.

Relative humidity (RH) and air temperature (measured by model HMP45C, Vaisala, Inc., Woburn, MA) screening identifies reasonable and unreasonable values. To determine if data is questionable or erroneous, local conditions must be known. Sensor calibration is needed if RH maximum values are in excess of $100 \%( \pm 5 \%)$ or if minimum values are frequently less than 30\% (Figure 8). During a continuous precipitation event, dew event, or during evening hours following an intense precipitation event, the $\mathrm{RH}$ values should be within $90-100 \%$.

Since the dew point temperature $\left(\mathrm{T}_{\mathrm{dew}}\right)$ is calculated from $\mathrm{RH}$, errors in the reported $\mathrm{RH}$ values will also be observed in the plotted $\mathrm{T}_{\text {dew. }}$. In this study area, which is classified as a humid region, it is common for the calculated $\mathrm{T}_{\mathrm{dew}}$ to approach the measured $\mathrm{T}_{\min }$ (Figure 9). Exceptions to this result from a change in air mass due to a frontal passage, or during days with high winds and/or cloudless nights. 


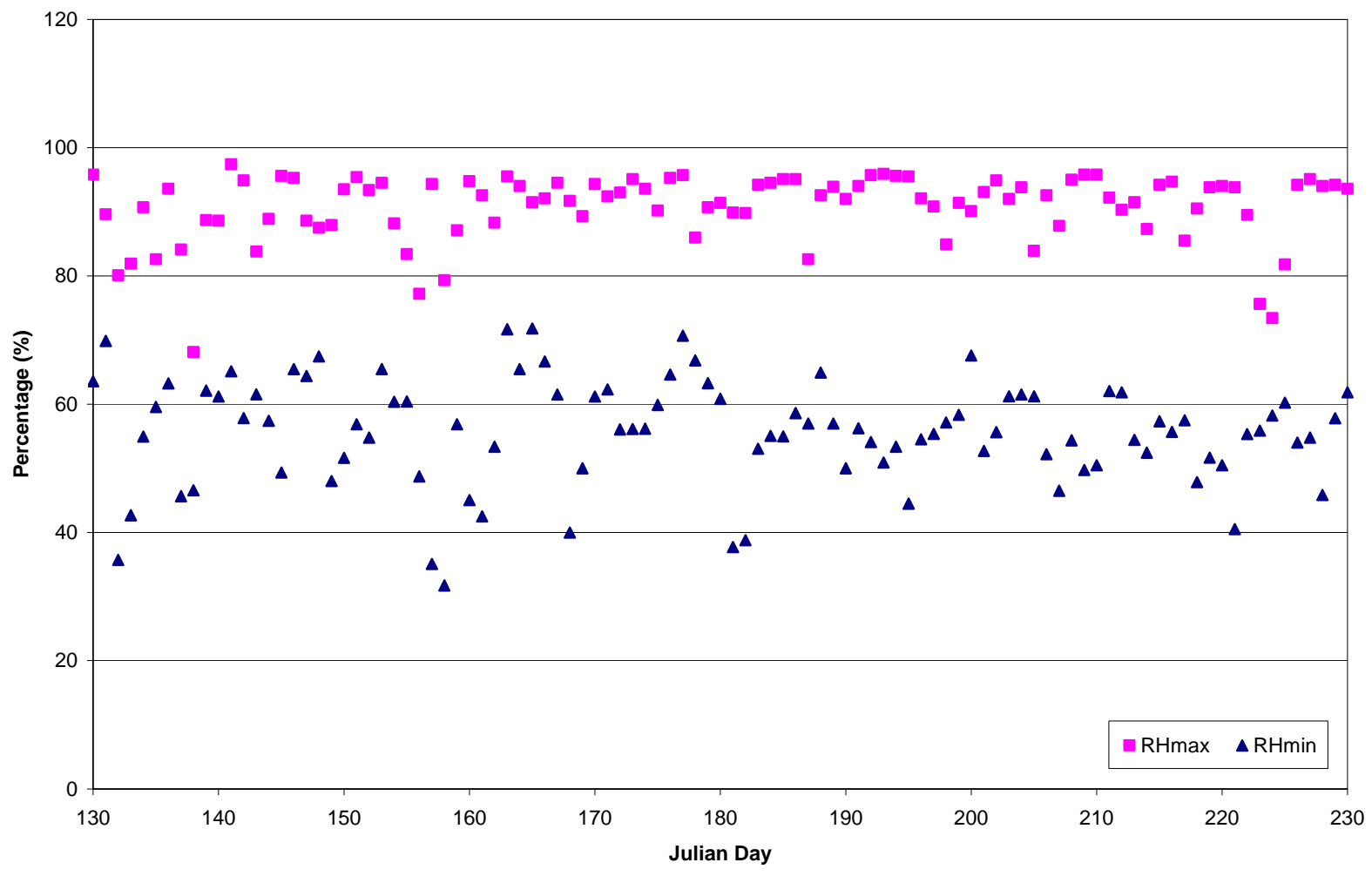

Figure 8. Daily maximum and minimum relative humidity recorded from Loc1, Palm Harbor, FL during

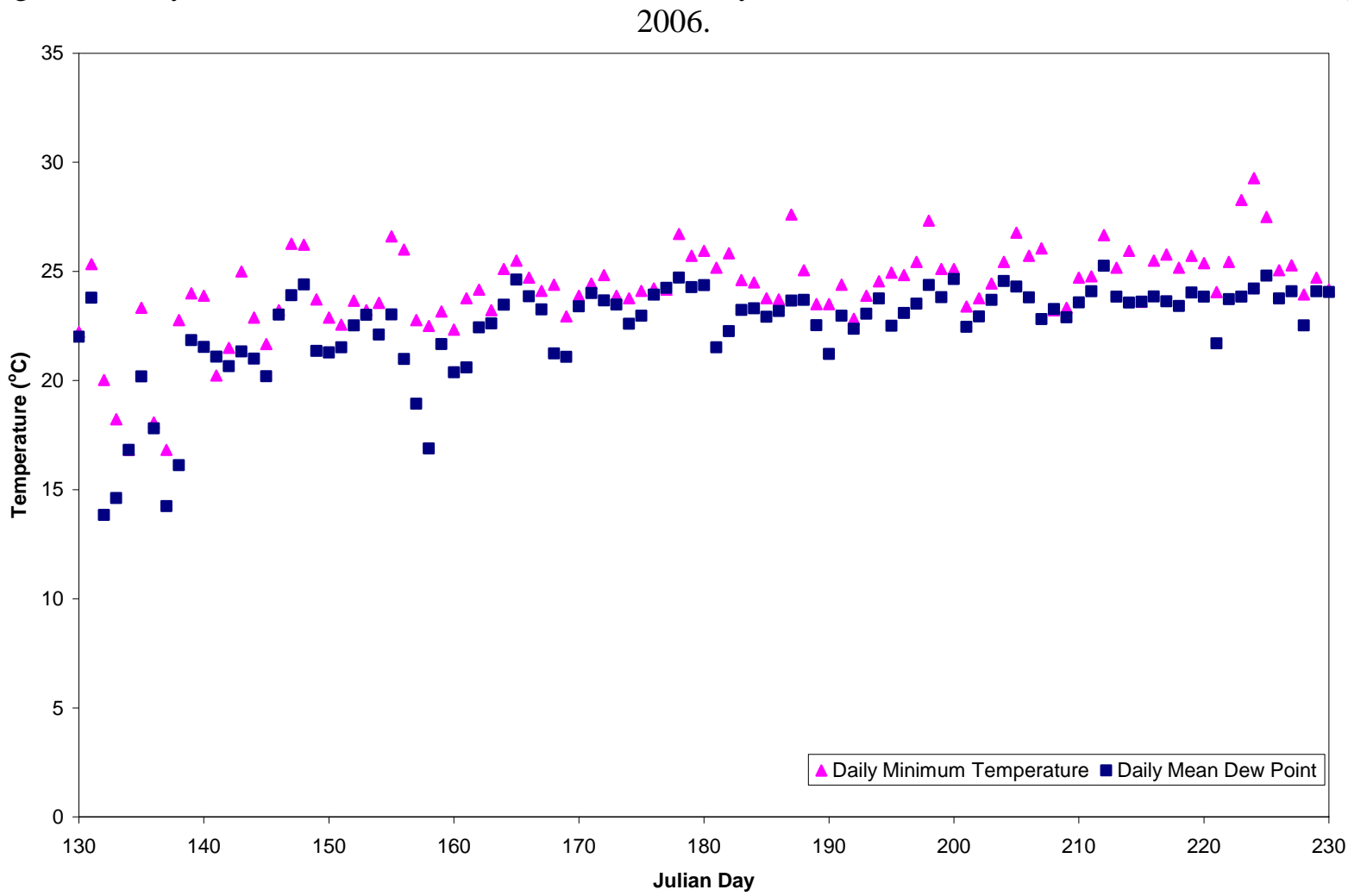

Figure 9. Measured daily minimum air temperature and mean daily dewpoint temperature recorded from Loc1, Palm Harbor, FL during 2006. 
Wind speed and direction is measured with an ultrasonic anemometer (model WAS425, Vaisala, Inc., Sunnyvale, CA). The gust factor is calculated as the ratio of maximum wind speed to mean daily wind speed. This ratio serves as an index for assessing wind speed accuracy. When plotting the gust factor over time, if the gust factor has exceptionally increased values, there may be a malfunction with the sensor. In this case, it is possible for the anemometer to malfunction for only a given period of time and then return to functioning normally. During hurricane season, the gust factor will result in high values during the storm event. The figure below depicts a normal functioning anemometer.

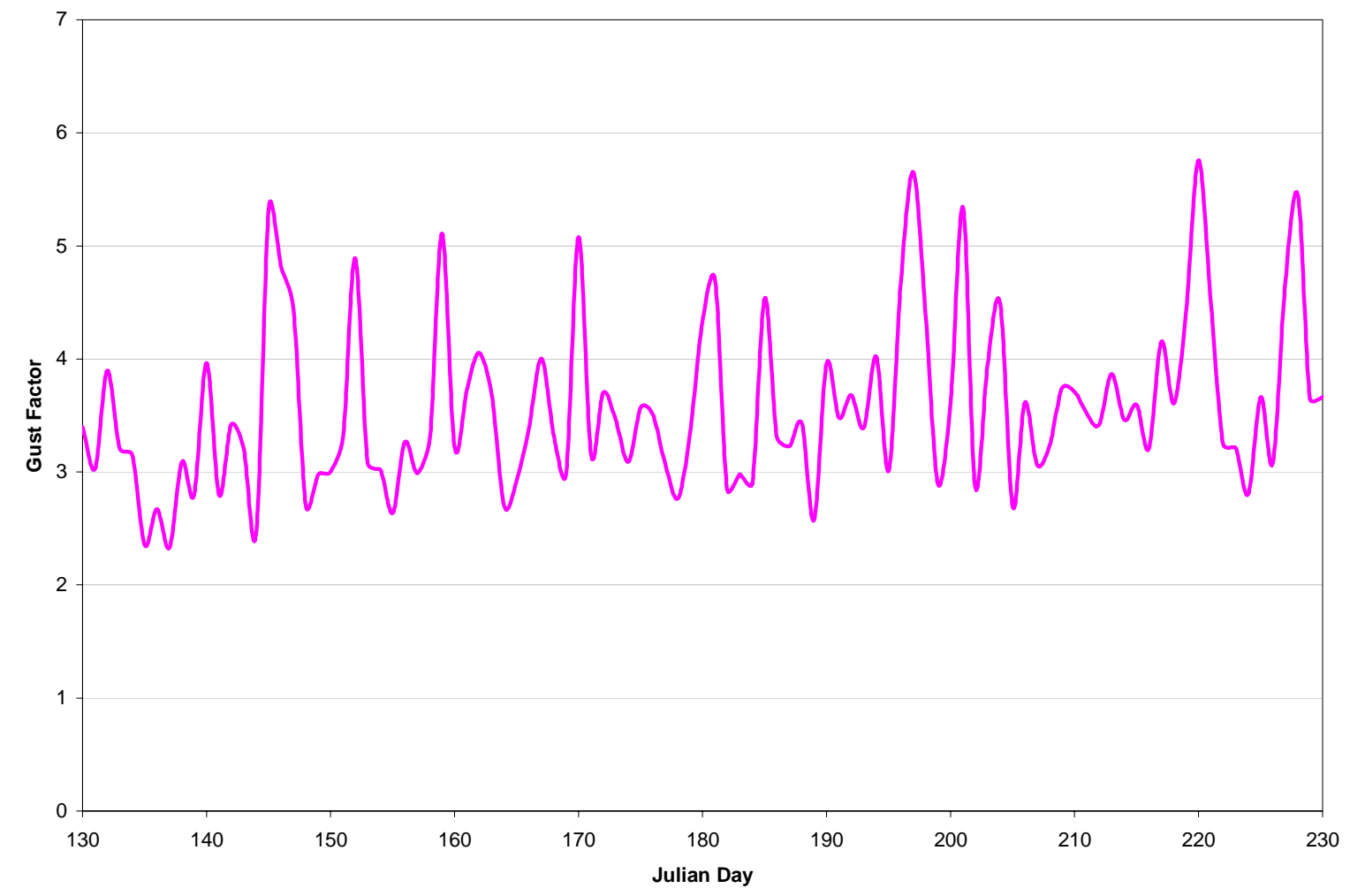

Figure 10. Ratio of maximum wind speed to mean daily wind speed recorded from Loc 1, Palm Harbor, FL during 2006.

As previously outlined, weather stations have been installed within each of the four described location areas. For weather data quality assurance, the calculated $\mathrm{ET}_{\mathrm{o}}$ at each station is compared (Figure 11). Station comparison provides a means to ensure sensor accuracy and offers an alternative data source in the event of missing records. Due to local variations in rainfall, different precipitation amounts for each location must be considered when calculating effective rainfall (Figure 11). At the time of this paper submission, weather data was only being collected at three of the four stations. 


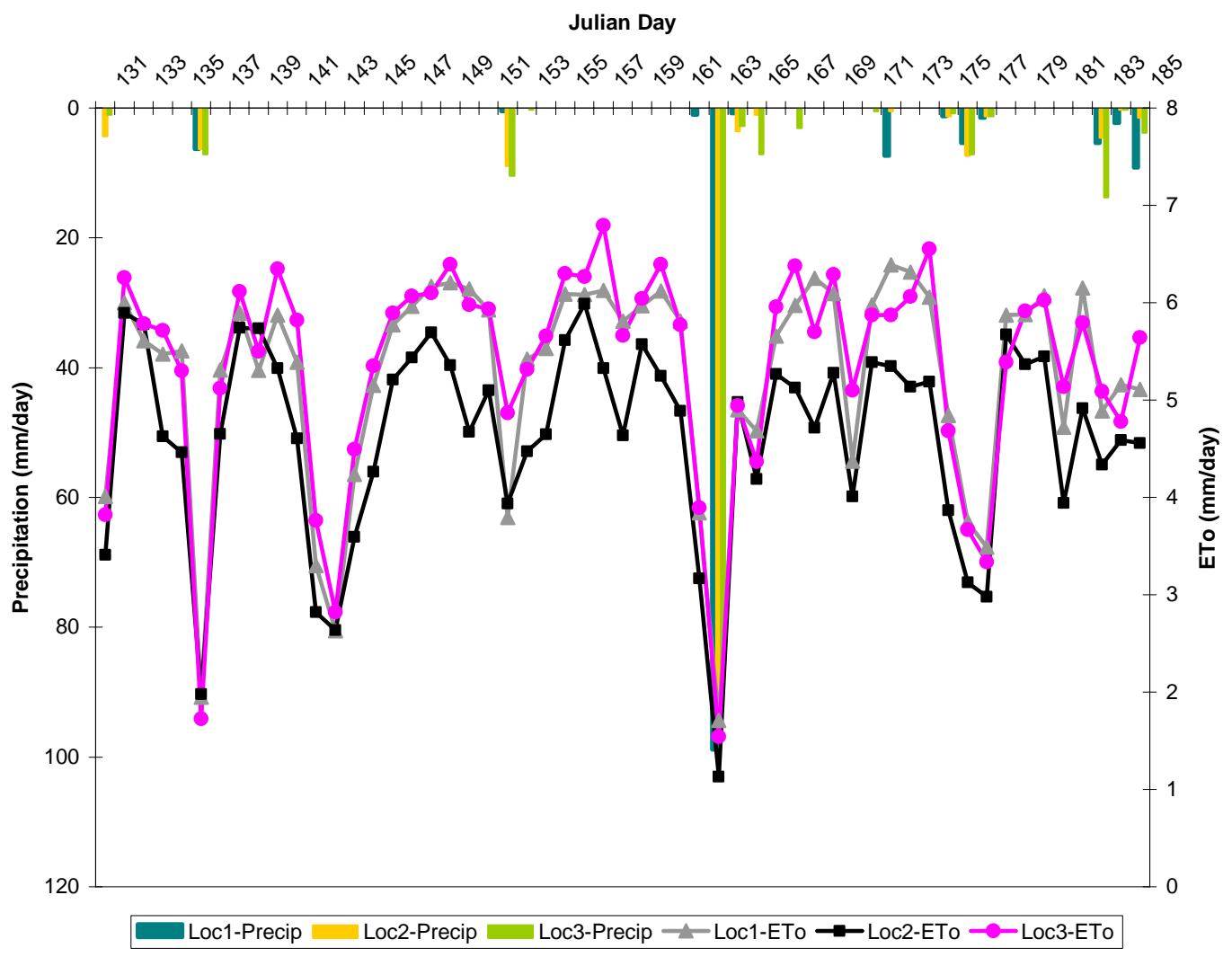

Figure 11. Calculated $\mathrm{ET}_{\mathrm{o}}$ and recorded precipitation from Loc 1, Loc 2, and Loc 3, Palm Harbor, FL during 2006.

\section{Initial Water Use Data}

Actual water use data collection began in the summer of 2006, initial results can be found in Table 2. Both total household water use and irrigation water use are recorded in gallons on a weekly basis. These data are collected by the Pinellas County Utilities Alternative Water Sources division. The individual households irrigated area is used to convert gallons of irrigation water used to depth (mm) of irrigation water applied. With both the total household water use and irrigation water use recorded from separate meters, it is possible to determine the percentage of water used for irrigation purposes. However, upon initial data collection, it was discovered that many of the city utility meters were in poor condition and required attention to result in proper data collection. Because of the replacement of multiple meters in week 3 , the gallon use recorded values were inconsistent and therefore the ratio of irrigation water use to total household consumption is not reported in this paper.

The irrigation water use application depths (Table 2) are compared based on treatment type, with homes within each location serving as treatment replications. Initial findings show the sensor based treatments (T1 includes a soil moisture sensor; T2 rain sensor; T4 having both a rain sensor and educational scheduling materials) to be using less water than the solely time controlled treatment (T3). T3 applied $283 \mathrm{~mm}$ of irrigation water in this first month of data collection. As expected, the T1 homes, with the buried soil moisture sensor have the lowest 
weekly use and have to lowest irrigation application amount in the first month, $12 \mathrm{~mm}$. The two treatments with rain sensors, T2 and T4, have similar weekly amounts, with the month total being slightly lower for T4.

Table 2. Recorded irrigation water use depth per week and monthly total depth applied.

\begin{tabular}{ccccc} 
& \multicolumn{4}{c}{ Actual Irrigation Water Use (mm) } \\
\hline & T1 $_{\text {avg }}$ & T2 $_{\text {avg }}$ & T3 $_{\text {avg }}$ & T4 $_{\text {avg }}$ \\
\hline Week 1 & 2 & 9 & 37 & 12 \\
Week 2 & 4 & 10 & 126 & 12 \\
Week 3 & 4 & 13 & 44 & 28 \\
Week 4 & 2 & 12 & 74 & 14 \\
\hline Std. Dev. & 4 & 11 & 40 & 13 \\
CV & 1.28 & 1.00 & 0.57 & 0.78 \\
\hline Month Sum & 12 & 43 & 283 & 66 \\
\hline
\end{tabular}

Compared to historical trends in irrigation water use based on a user profile for the sample population (Table 1), the irrigation amounts are within the expected normal values. From these classifications, the minimum monthly irrigation water consumption amount for a "low" user was $20 \mathrm{~mm}$. From this initial actual water use data, T1 falls below the low range, as would be expected. T2 and T4 fall within the lower spectrum of the water use for homes in the "medium" classification. The monthly total for T3 $(283 \mathrm{~mm})$ is greater than the maximum for the "high" classification (218 $\mathrm{mm})$.

\section{Future plans}

Weekly irrigation water use and continuous weather data continue to be collected. When a sufficient duration of data has been collected, appropriate statistical analyses will be performed on the treatment divisions to quantify differences between water use considering sensor type and the distribution of educational materials. The weather data is downloaded monthly from the weather stations. Additionally, turf quality analysis will continue to be monitored on a seasonal basis. It is expected with the incorporation of soil moisture sensors, rain sensors, and educational materials, to help home owners implement their irrigation schedule; irrigation water application will be reduced. 


\section{Acknowledgements}

The authors thank the Pinellas-Anclote Basin Board of the South West Florida Water Management District, the Florida Nursery Growers and Landscape Association, the Florida Turfgrass Association, and the Florida Agricultural Experiment Station for funding support. In addition, the authors appreciate the assistance of Bernardo Cardenas, Larry Miller, Danny Burch, Wayne Williams, Mary Shedd, and Stacia Davis.

\section{References}

ASCE-EWRI. 2004. The ASCE Standardized Reference Evapotranspiration Equation. Technical Committee report to the Environmental and Water Resources Institute of the American Society of Civil Engineers from the Task Committee on Standardization of Reference Evapotranspiration. Reston, VA.

Baum, M.C., M.D. Dukes, and G.L. Miller. 2005. Analysis of Residential Irrigation Distribution Uniformity. Journal of Irrigation and Drainage Engineering. 131(4):336-341.

Baum, M.C., M.D. Dukes, and D.Z. Haman. 2003. Selection and Use of Water Meters for Irrigation Water Measurement. Florida Cooperative Extension Service, Institute of Food and Life Sciences, ABE 18. University of Florida, Gainesville, FL. Available at: http://edis.ifas.ufl.edu/AE106. Accessed 19 September 2005.

Cardenas-Lailhacar, B, .D. Dukes, and G.L. Miller. 2005. Sensor based control of irrigation in bermudagrass. ASAE Meeting Paper 052180. St. Joseph, Mich.: ASAE.

Florida Statutes, Chapter 373.62: Water conservation; automatic sprinkler systems. Available at: http://www.floridadep.org/water/stormwater/npdes/docs/ch373.pdf. Accessed 16 February 2006.

Haley, M.B. M.D. Dukes, and G.L. Miller. 2006. Residential Irrigation Water use in Central Florida. Journal of Irrigation and Drainage Engineering. In review.

Irrigation Association. 2005. Turf and landscape irrigation best management practices. Irrigation Association Water Management Committee, Falls Church, VA.

Merriam, J.L. and J. Keller, 1978. Farm Irrigation System Evaluation: A Guide for Management. Department of Agricultural and Irrigation Engineering, Utah State University, Logan, Utah, USA.

Micker, J. 1996. Mobile Irrigation Laboratory Urban Irrigation Evaluation Training Manual. U.S. Department of Agriculture. Gainesville, FL.

PCU. 2006a. Pinellas County Utilities Water \& Sewer Rates. Clearwater, FL. Available at: http://pubgis.co.pinellas.fl.us/pcuweb_live/water/restrictions.cfm. Accessed 30 May 2006.

PCU. 2006b. Pinellas County Utilities Water \& Sewer Rates. Clearwater, Florida. Available at: http://pubgis.co.pinellas.fl.us/pcuweb_live/whatsnew/water_sewer_rates_update.cfm. Accessed 30 May 2006.

Shearman. R. C. and K. N. Morris. 1998. National Turfgrass Evaluation Procedure Workbook. NTEP Turfgrass Evaluation Workshop, October 17, 1998, Beltsville, MD.

SWFWMD. 2005. Southwest Florida Water Management District Water Management Plan. Brooksville, FL. Available at: http://www.swfwmd.state.fl.us/about/watermanagementplan/. Accessed 30 May 2006

Whitcomb, J.B. 2005. Florida water rates evaluation of single-family homes. Southwest Florida Water Management District. Brooksville, FL. 


\section{Appendix}

Table A1. Uniformity test results from irrigation evaluations.

\begin{tabular}{|c|c|c|c|c|c|}
\hline House No. & $\mathrm{DU}_{\mathrm{lq}}$ & $\mathrm{DU}_{\mathrm{lq}}$ Rating & House No. & $\mathrm{DU}_{\mathrm{lq}}$ & DU $_{\text {lq }}$ Rating \\
\hline 2860 & 0.29 & fail & 486 & 0.66 & good \\
\hline 3620 & 0.32 & fail & 252 & 0.66 & good \\
\hline 105 & 0.33 & fail & 1694 & 0.67 & good \\
\hline 3013 & 0.34 & fail & 4926 & 0.67 & good \\
\hline 325 & 0.36 & fail & 4849 & 0.68 & good \\
\hline 3022 & 0.38 & fail & 2936 & 0.68 & good \\
\hline 1521 & 0.44 & poor & 2196 & 0.68 & good \\
\hline 513 & 0.44 & poor & 2980 & 0.68 & good \\
\hline 1543 & 0.46 & poor & 128 & 0.7 & very good \\
\hline 217 & 0.49 & poor & 101 & 0.72 & very good \\
\hline 633 & 0.5 & fair & 3001 & 0.72 & very good \\
\hline 515 & 0.5 & fair & 351 & 0.73 & very good \\
\hline 3528 & 0.51 & fair & 131 & 0.73 & very good \\
\hline 3037 & 0.52 & fair & 2302 & 0.76 & excellent \\
\hline 3135 & 0.53 & fair & 2790 & 0.76 & excellent \\
\hline 3906 & 0.57 & fair & 148 & 0.76 & excellent \\
\hline 3994 & 0.57 & fair & 4881 & 0.8 & excellent \\
\hline 2207 & 0.58 & fair & 2954 & 0.8 & excellent \\
\hline 3835 & 0.59 & fair & 4958 & 0.82 & excellent \\
\hline 3061 & 0.6 & good & 2829 & 0.83 & excellent \\
\hline 2879 & 0.62 & good & 3925 & 0.85 & excellent \\
\hline 3040 & 0.63 & good & Min & 0.29 & \\
\hline 3925 & 0.64 & good & Max & 0.85 & \\
\hline 2852 & 0.65 & good & Mean & 0.61 & \\
\hline 3701 & 0.65 & good & Std Dev & 0.15 & \\
\hline
\end{tabular}


Table A2. Initial data collection for homes with one month of complete data as on 7/14/2006, water use data presented in mm/wk of irrigation application.

\begin{tabular}{|c|c|c|c|c|c|}
\hline TMT & Rep & Week 1 & Week 2 & Week 3 & Week 4 \\
\hline \multirow{4}{*}{$\mathrm{T} 1$} & R1 & 5 & 11 & 0 & 0 \\
\hline & R2 & 0 & 4 & 7 & 0 \\
\hline & R3 & 2 & 2 & 0 & 0 \\
\hline & R4 & 0 & 0 & 9 & 9 \\
\hline Week & Average & 2 & 4 & 4 & 2 \\
\hline \multirow{9}{*}{$\mathrm{T} 2$} & R1 & 11 & 21 & 27 & 22 \\
\hline & R2 & 0 & 0 & 29 & 24 \\
\hline & R3 & 0 & 0 & 0 & 0 \\
\hline & R4 & 24 & 20 & 19 & 12 \\
\hline & $\mathrm{R} 5$ & 0 & 0 & 0 & 0 \\
\hline & R6 & 23 & 23 & 31 & 10 \\
\hline & R7 & 0 & 0 & 0 & 0 \\
\hline & R8 & 13 & 18 & 14 & 14 \\
\hline & R9 & 6 & 5 & 0 & 22 \\
\hline \multicolumn{2}{|c|}{ Weekly Average } & 9 & 10 & 13 & 12 \\
\hline \multirow{8}{*}{ T3 } & R1 & 42 & 79 & 61 & 76 \\
\hline & R2 & 14 & 13 & 27 & 27 \\
\hline & R3 & 36 & 25 & 40 & 40 \\
\hline & R4 & 0 & 542 & 33 & 410 \\
\hline & $\mathrm{R} 5$ & 94 & 95 & 50 & 31 \\
\hline & R7 & 77 & 32 & 53 & 21 \\
\hline & R8 & 29 & 30 & 56 & 3 \\
\hline & R9 & 0 & 189 & 35 & 3 \\
\hline \multicolumn{2}{|c|}{ Weekly Average } & 37 & 126 & 44 & 76 \\
\hline \multirow{5}{*}{$\mathrm{T} 4$} & R1 & 16 & 16 & 23 & 26 \\
\hline & R2 & 0 & 0 & 0 & 10 \\
\hline & R3 & 7 & 14 & 39 & 19 \\
\hline & R4 & 13 & 10 & 32 & 0 \\
\hline & R5 & 22 & 19 & 47 & 16 \\
\hline \multicolumn{2}{|c|}{ Weekly Average } & 12 & 12 & 28 & 14 \\
\hline
\end{tabular}

